\title{
The Most Poetic Subject in the World
}

\author{
By Valerie Su-Lin Wee \\ Spring 1997 Issue of KINEMA

\begin{abstract}
THE MOST POETIC SUBJECT IN THE WORLD: OBSERVATIONS ON DEATH, (BEAUTIFUL) WOMEN AND REPRESENTATION IN BLADE RUNNER
\end{abstract}

WESTERN culture has a long tradition of associating death with femininity and sex. Whether it is Snow White or Bluebeard's wives, Clarissa or Madame Bovary, Carmen or Madame Butterfly, representations of dead and dying women fascinate and disturb. A Greek motto from Palladas states that "Every woman is as bitter as gall; but she has two good moments, one in bed, the other at her death" (quoted by Mérimée, 181). According to Edgar Allan Poe, "the death of a beautiful woman is, unquestionably, the most poetic subject in the world" (19). Thomas de Quincey acknowledges ". . . with the love that burns in depths of admiration . . . that you [sister woman] can do one thing as well as the best of us men -- a greater thing than even Milton is known to have done, or Michael Angelo: you can die grandly, and as goddesses would die, were goddesses mortal" (406). This tradition of conjoining the concepts of death and femininity, along with the tendency to view it as grand or profound, endures in contemporary culture and is most successfully articulated in film. What follows is a detailed analyses and discussion of how the traditionally related notions of death and femininity are treated in one contemporary science-fiction film: Blade Runner. ${ }^{(1)}$ The ways in which the dead and dying woman is explicitly objectified and spectacularised in death, the tendency and means by which the violence and horror of a woman's death is often obscured or muted, the relationship between death, the feminine and sexuality, and the significance of their dead bodies will all be discussed.

In Blade Runner, the females ${ }^{(2)}$ do not possess any significant roles; they never appear to affect the narrative of the film, their appearances have little effect in terms of advancing the plot and they are seldom seen in any active roles for they are characterised as largely passive objects; they are ineffectual and inconsequential characters whose only function, in the film, appears to be to die spectacularly. In fact, there are only two scenes in Blade Runner in which the replicant women are vital and indispensable: their death scenes. These scenes explicitly articulate the stereotypical notions that consider overt female sexuality a threat, reducing women to objects and portraying the death of a woman as a grotesque and stunning spectacle.

In the scenes leading up to Zhora's death, she is shown returning to her dressing room after performing an erotic sex act on stage. She is intercepted by Deckard who gains entry into her dressing room disguised as a "member of the Committee against Moral Abuses". While questioning Zhora about her working conditions, Deckard surreptitiously searches the room for clues to the whereabouts of Zhora's fellow replicants. Throughout the scene, Zhora appears friendly, unsuspecting and coyly sexual. Coming out of the shower, she makes no attempt at modesty and tosses a towel at Deckard, inviting him to dry her while she dresses in a bikini outfit. It is immediately after this sexually suggestive invitation that Zhora launches into her sudden and unexpected attack on Deckard. Having Zhora attack ferociously within this sexualised context effectively associates female sexuality with savage violence, marking it as perverse and terrifying. Before Zhora is able to kill Deckard, however, she is interrupted by a group of people, which prompts her to flee the scene, leaving Deckard to pursue her through the city streets. After a short chase, Deckard catches up with Zhora and shoots her repeatedly in the back as she struggles to escape from him. As Deckard fires, Zhora is shown crashing, in slow-motion, through a series of plate glass windows, windows in which female mannequins are on display wearing sexy lingerie (which, hardly by coincidence, resemble what Zhora herself has on) and positioned amidst garish neon lights. After the slow motion sequence, there is a sudden, quick cut to a shot of Zhora's body lying face down on the ground, her body stiff, with a glazed look in her still open eyes, resembling a toppled mannequin, remarkably similar to the very mannequins in the display windows she had been running past. In death, therefore, Zhora is reduced to a broken doll, an inanimate object. A similar treatment of Pris occurs later in the film.

Deckard, having concluded that the surviving replicants are hiding at JF Sebastian's house, goes there to complete his assignment. Pris, left alone in the apartment, hears Deckard and attempts to hide herself by disguising herself as a life-size doll or mannequin, posing, motionless, amongst the other dolls and mannequins in the apartment. Pris, therefore, assumes the pose of passivity as a disguise. This is easily accomplished for 
she had earlier painted herself to resemble the grotesque image of a doll with a startlingly pale face, a black "mask" of paint over her eyes and lips and her shock of hair resembling a wig. Pris, therefore, turns herself into a life-size doll. Thus, when Deckard first enters the room in which Pris is hiding, he fails to discover her. It is only after several suspenseful moments that he approaches the stiff, apparently lifeless figure of Pris for a closer look.

It is at this moment that Pris explodes into violent action, taking Deckard by surprise. During the attack, Pris is shown clamping Deckard's head between her thighs, presenting a sexually suggestive image. The scene is doubly shocking because as Pris attacks, she shrieks and screams like a banshee possessed; the terror is heightened by the use of tight, close-up shots of Pris looking like a demented, grotesque witch with her hair standing on end and a crazed look in her heavily made up eyes; that these shots are taken from a very low angle so that the audience is positioned beneath the image, and "forced" to look up at it serves to heighten the horror since, from the audience's point of view, the shot of Pris is huge and overwhelming. While Pris is gearing up for a second assault on Deckard, however, she is shot in mid-somersault. Unfortunately, she fails to die immediately, and instead is shown thrashing around wildly, writhing and shrieking on the floor. It is at this point that Deckard shoots Pris again to finish the job.

While these scenes are highly disturbing, particularly in terms of the misogyny they portray, this anxiety is largely dissipated because the portrayals of both Zhora and Pris are so disturbing and grotesque that one is almost glad that Deckard has destroyed them and thus relieved the audience of their perversity. In fact, as Deckard fatally shoots Pris, the audience is awarded another spectacle, also in slow motion sequence, of a woman's death, for we get to see the bullet hit Pris and her entire body ricochet from the impact of the shot. Like Zhora before her, there is a similar cut to Pris's inert body, lying against the wall resembling, again, nothing more than a broken doll, with its painted face and crumpled limbs. The ways in which the dead and dying woman is transformed into artistic, aesthetic images, even whilst they represent images of extreme and grotesque violence is worth detailed analysis and comment.

In the death scene of Zhora, we have "an image of a beautiful dead woman exhibited for the gratification of her viewers" (Bronfen, 100). It is noteworthy that Zhora's takes place behind large, plate glass windows, windows constructed to frame that which is meant to be displayed and viewed from all angles, for just as the mannequins housed in the window displays are constructed and arranged for viewing and display, so too is Zhora's death scene constructed for the viewing pleasure of the film's audience. The use of colour, the grace and control with which Zhora's body is seen to crash through the glass, the shattering and flying pieces of glass as she breaks through, all combine to construct a series of extremely beautiful images. Even the soundtrack is manipulated to heighten the visually aesthetic construction of the scene, emphasising the atonal music on the soundtrack, the sound of breaking glass, the throb of heartbeats and a female voice screaming. Each sound is heightened and "prolonged" so that they appear to match the slow-motion sequence. Zhora's body is reduced to the function of an exhibit as it lies lifeless and inert, "displayed" in a glass "coffin". The aesthetically involved spectator is sufficiently distanced by these stylised, aesthetic images that s/he treats the representation of the dying body only as a signifier pointing to other signifiers (for example the other images constructed in the film, or other available cultural images), so that the very image being represented, the particular image of a specific woman's experience of death, is obscured and forgotten in favour of the significance of how the image is produced. This can succeed to the point that the horror and violence that is imposed on a woman's body is all but obscured by the stunning beauty of the images. Elisabeth Bronfen has suggested that

Death and femininity are culturally positioned as the two central enigmas of western discourse .... [representing] that which is inexpressible, inscrutable, unmanageable, horrible; that which cannot be faced directly but must be controlled by virtue of social laws and art (255).

And in the scenes analysed above, femininity is indeed constructed to represent the "inexpressible, inscrutable, unmanageable, horrible"; it is also traditionally a sign of Otherness as the uncontrollable unknown. Zhora and Pris are both instances of Woman as evil, destructive, deviant Other. In each case, they are portrayed as figures who threaten order and safety; both are extremely violent characters. Both women's attacks on Deckard are shocking and terrifying for they occur at unexpected moments and are carried out with great ferocity and skill. Both attacks occur without warning and without any overt threat from Deckard; in both 
instances, he is caught completely off-guard.

Zhora and Pris are further marked as deviant and perverse by their inhuman strength and skill. Both women appear to be virtually unbeatable in unarmed combat. Zhora's great strength is evident in her ability to fling Deckard across her dressing room effortlessly. She is also seen attempting to strangle him with her bare hands. Zhora is foiled in her attempts only by an opportune interruption. Pris's attack on Deckard is similarly marked as threatening and terrifying. After her initial attack, Deckard attempts to get away from her but fails, for Pris comes somersaulting out of the dark, through the dimly lit apartment and lands on Deckard, knocking him to the ground. Thus, Deckard is shown to be incapable of escaping Pris's relentless pursuit of him. During their struggle, the images of Pris are particularly disturbing and frightening for it is Pris's grotesque, unnaturally made- up face that the audience sees staring down at Deckard while he is pinned under her, his head trapped between her thighs, as she shrieks and screams at him while thrashing at his head with her arms. Thus both Zhora and Pris are marked as deviant, evil, terrifying creatures who do not appear human; rather, they appear as extreme representations of femininity -- they are the monstrous feminine, who threaten the order and safety established by patriarchal law and defended by Deckard. Thus we can see that representations of Woman as a terrifying, disruptive force are constructed to

[serve] rhetorically to dynamise a social order, while her death marks the end of this period of change. [And it is] over her dead body [that] cultural norms are reconfirmed or secured ... because a sacrifice of the dangerous woman re-establishes an order that was momentarily suspended due to her presence (Bronfen, 181).

The destruction of Zhora and Pris can therefore be read as the destruction of a threatening, disruptive element which, if left to endure, would lead to ultimate chaos and destruction, for these women are representations of that Otherness which these films define as agents of destruction and the embodiments of pure and unadulterated violence. They represent the evil which challenges that stability and order established by the patriarchal system. In these instances, therefore, the Woman is killed as a substitute. For in these films, all that is evil, perverse, destructive and dangerous is externalised and projected onto these women so that these negative qualities can be given a tangible body which can be hunted down, punished and destroyed.

These women, therefore, simultaneously represent both the subject's own sadism and, as the Other, the strange and potentially hostile body. Thus, in cultural representations, the elimination of a feminine body serves as a means of re-establishing and re-inscribing that order and stability which is continually threatened by the negative qualities the bodies of these women are made to embody and represent. What is controlled with the killing of Zhora and Pris is Otherness as constant volatility, as sexual difference, and as evil's presence in life in the form of the numerous negative qualities and aspects associated with their characters. What is controlled is Otherness, when this Otherness functions as a force disruptive of the security of order, of clear oppositions and stable identities (Bronfen, 189). Thus, these female characters are violently punished with the death sentence for transgressing social laws and boundaries. Zhora and Pris must be held accountable for their disregard for the law that bans them from earth, their rejection of the roles and positions prescribed for them, their excessive sexuality and their destructive, threatening violence. In each instance, these women's primary crime appears to be their rejection of the patriarchally approved brand of femininity which advocates the qualities of obedience, submission, weakness and inferiority for women.

It is also worth noting that in every instance, the women are made to appear extremely terrifying and menacing because they seem to attack and destroy for little apparent reason. The fact that Zhora and Pris attack Deckard in self-defence, since Deckard, who was fully aware of their identity, was going to destroy them, is neatly obscured behind the shocking outbursts of violence from the women. In addition, the fact that the women are "replicants", "artificial humans" and therefore not "real", also assuages any guilt or anxiety associated with their violent deaths.

As a result, the extreme violence with which these women are treated is obscured and even justified by the fact that the scenes are constructed to suggest that the men are acting in self defence. Thus, there appears to be an exchange in which Woman is substituted for the other guilty person; in every scene in which a woman in killed, it would be logical to assume that the killer is guilty of murder while the women are the victims, yet this does not generally appear to be the case -- although Deckard admits to "shooting a woman in the back", the audience's sympathies lie largely with him while Zhora's death is easily dismissed. The 
same occurs when Pris is killed.

Also worthy of discussion is the way in which a clear, precise boundary appears to be established and affirmed over the site/sight of the female dead body, between such opposing concepts as the self and Other, which implies other such primary distinctions as those between living and dead, good and evil, right and wrong. In each instance, all that is negative is displaced on the dead body of the female Other, while the opposing positive qualities are represented by the surviving self. This generally results in the creation of the impression of "goodness triumphing over evil", which appeals to the audience's sense of justice. Therefore, in addition to the extreme violence that is exacted on the female body, additional violence is perpetrated when the woman ceases to be considered an individual; rather, her dead body is reduced to the status of a sign, a signifier of a variety of qualities outside of her existence as an individual, for "the interstice between death, femininity and aesthetics is negotiated over the representation of a dead feminine body clearly marked as being Other, as being not mine." (Bronfen, xi).

Rather, the dead body of a woman functions like the fetish; the representation of a dead woman is 'uncanny' in that she frightens and reassures, in that she functions simultaneously as a site of lack and what covers the lack. Analogous to the way the sight of the corpse imbues the survivor with a sense of mastery over death, this spectacle of 'sexual' lack allows the viewer to isolate his own Otherness, by translating it onto a sexually different body, and in doing so it works once again on the principle of an interchangeability between dead and feminine body. Thus, the violent acts of dying in which these women are caught can be read as representations of an arrestation of/by death of the destructive force of nature.

It is interesting that in each instance, the dead woman's body becomes the focus of the male gaze. (3) After the death of both Zhora and Pris, there are shots of Deckard standing over these dead women, gazing intently down on them. Deckard is, therefore, constructed as the active superior male subject in the scene, the bearer of the gaze, looking down on the inert, dead objects that are the women's bodies. According to Elias Canetti, death is often ascribed to a feminine position while perceiving survival as masculine, for the moment of survival becomes a moment of power and triumph. The horror that is felt at the sight/site of death is transformed into satisfaction because the survivor is not himself dead. In addition, the fact that the dead body is in the passive, horizontal position, cut down, fallen while the survivor stands erect, imbued with a feeling of superiority, codes the corpse as feminine, the survivor as masculine (cited by Bronfen, 65). While Bronfen stipulates that "such gender designations are figurative and do not conform to biological reality", it is worth noting that in all of these films, the survivor is almost always biologically male. And this male survivor can now celebrate the feminine corpse for "insensible and impenetrable, the body becomes phallic". According to Bronfen, "as a corpse, the feminine body loses her quality of being Other, and becomes the site where the-gazed-at-object and the object desired by the gazing subject merge perfectly into indistinction" (98-99). In her death, the threat of Otherness, her lack or excess is neutralised, any power that is situated in the woman, any threat that she poses no longer exists. As a result, the surviving male subject, who has proved his power, his authority and his legitimacy by killing the deviant Other, can now gaze down upon the female victim and mourn.

The male gaze also effectively transforms the women's dead bodies into objects to be looked at and gazed upon. Zhora's dead body is made to visually resemble a toppled mannequin, a reflection of the numerous mannequins that she had run past as she crashed through the window displays, glass windows that house representations of woman and femininity that are sexually coded as well as products for consumption. Thus, Zhora's body is associated with (and reduced) to these inanimate and artificial images of the feminine. Pris's dead body is constructed to resemble a broken doll, flung up against a wall and left where it fell.

In both cases, Zhora and Pris, in death, are reduced to inanimate objects, they are representations of other representations (dolls and mannequins) of an idealised notion of femininity -- they are living, animate dolls constructed by men who are then reduced to reflections of inanimate dolls when they are killed. That Pris herself is seen actively transforming herself into the image of a plastic doll is a tragic comment on the limitations imposed on her by the patriarchal law she lives under; where the male replicants become more and more human as the film progresses, it is significant that the female replicants are seen to become more and more like dolls and mannequins. Thus, Zhora and Pris, as the film progresses, become increasingly alienated and removed from any realistic ideas or images of (human) femininity. Elisabeth Bronfen suggests 
that

the fascination engendered when dead females are visually reduced into 'doll-like' images has to do with the fact that the two enigmas of western culture, death and female sexuality, are here 'contained' in a way that exposes these two conditions to a sustained and indefinite view, but does so in such a way that the real threat of both, their disruptive and indeterminate quality, has been put under erasure (99).

Sander Gilman points out that these instances of reducing the animate into inanimate dolls serve to cover, distance and control both sexuality and death by rendering the mutable, dangerously fluid, destabilised feminine body in a cleansed, purified, immobile form that signifies less its object of material reference than the survivor and in part the implied gaze of its spectator (104). By virtue of this transformation, the dead female body is turned into an object of art which elicits and allows a kind of spectatorship which Norman Bryson has defined as "the activity of the gaze: a prolonged, aloof disengaged form of contemplation across a tranquil interval" (94).

And it is across this "tranquil interval", after Deckard finally manages to kill Zhora, that he states in his voice-over that "the report would be routine retirement of a replicant, which didn't make me feel any better about shooting a woman in the back. There it was again: feeling, in myself, for her, for Rachel.". It appears extremely convenient to feel bad "about shooting a woman in the back" after the fact. Significantly, Deckard never showed any hesitation in shooting Zhora in the back numerous times while he was doing it; the "feeling" came only as he was gazing down at her lifeless body. Deckard, therefore, is speaking from a position of safety and as a survivor. Thus, Zhora's corpse functions as that onto which Deckard can project a range of emotions. In the midst of articulating these emotions, however, Deckard effectively dismisses the significance of Zhora's body, focusing instead upon his thoughts and his developing emotions, thus negating Zhora's body even as he gazes upon it.

This rhetorical transformation of Zhora's body into an inanimate figure, with the semantic coding that is exterior to any personally chosen meaning, serves as an example of what Teresa de Lauretis considers rhetorical violence. ${ }^{(4)}$ From this discursive position, the heroic attempt that Deckard makes to recognise death over Zhora's dead body, to fulfil his mourning, looks like an expropriation of the feminine body, a reduction of the body to an object, externally coded; it is a means by which the reality of Zhora's death is obscured and neglected in favour of highlighting Deckard's developing humanity, emotional growth and empathy. What is violent about Deckard's action is that it displaces the point of view from the pain and the terror of the dead woman, subordinating them to notions of the surviving subject's consciousness and character and aesthetic effect.

This treatment is imposed on Pris's dead body also. After killing her, Deckard walks over to gaze down at her lying in a crumpled heap against a wall. Deckard's survey of Pris's body is interrupted by Batty's entrance. Hearing Batty's arrival, Deckard runs off to hide. When Batty discovers Pris's body, his deep sorrow and anger at Pris's death is evident. After planting a kiss on her lips, he dips his fingers in her blood and uses it to paint his face in imitation of war stripes. Where Deckard appropriates Zhora's body and uses it as the sign over which he articulates his growing sensitivity and empathy for the replicant condition, Batty uses Pris's body and blood for his own signification, he uses her blood to mark his pain, his sadness, his anger; thus further displacement of the dead woman's individual meaning occurs in the form of a semiotic reappropriation of her death, for Pris's blood, which is symbolic of her death, is used here as a signifier for the heroic qualities of pathos and nobility associated with Batty.

The violence of Pris's death, the significance of her body is obscured. Thus, Deckard and Batty (and director Ridley Scott) appear to be denying Zhora and Pris their pain, their individual meaning, denying them a possibility of signifying other than in relation to the male survivors. The death of a woman, therefore, appears as condition and pretext for a meaning that lies elsewhere and allows the male perpetrator and spectator a stable position before the death of the other and thereby implicitly his own death. For as Elisabeth Bronfen recognises,

to represent over her dead body signals that the represented feminine body also stands in for concepts other than death, femininity and body -- most notably the masculine artist and the 
community of the survivors. These find an allegorical articulation even though they are not the literal meaning of the image .... In so doing [the image] fades from our sight and what we see, whenever an aesthetic representation asks us to read topically, is what is in fact not visibly there .... Rather, the gesture of an aesthetic substitution is such that what is literally represented -femininity and death -- often entirely escapes observation (xi).

What does not escape observation is the highly sexual nature of these scenes. Zhora performs sex acts on stage, and prior to her attacking Deckard is seen to act very sexually. When Zhora dies, she is surrounded by scantily dressed mannequins. Pris is a prostitute and the way in which she attacks Deckard, catching his head between her thighs, is extremely sexual. Thus, the treatment of all these women appears to conform to the stereotype derived from Eve. These women serve as the allegory of sin, deception, evil, destruction -they are the superlative embodiments of dangerous sexuality. Rather than signifying the source of fertility and healing, these women are constructed as polluted, as the agents and carriers of death.

In each of these instances, the strong association of sexuality with death may be seen to be reflections of a culture "whose general attitudes toward sexuality are negative ..., [a culture] which attaches great penalties to a promiscuity in women it does not think to punish in men" (Millett, 123), as evidenced by the cultural tendency to code female sexuality in extremely harsh terms: it is generally marked as excessive, perverse and destructive.

From a psychoanalytic standpoint, Freud maintains that death sanctions what would otherwise be a perversion -- it excludes the sexual activity connected with touching the other. The aesthetic staging of these women's deaths masks "perversity", for it forecloses touch, displaces touch onto the gaze, transforms the gaze into a form of touch. At the same time,

the gendering of the dead displayed body, which occurs when it is semantically coded as a figure of 'feminine beauty', not only veils death but also induces a blindness towards a subjectivity of the corpse as this includes its sexual alterity. (Bronfen, 102).

When the images of the dead or dying are gendered as "female", as "Other" and particularly as "deviant Other", these images enable

death as state or process [to be] focalised externally, [allowing] both [to be] totally appropriated by the viewer's fantasies and totally inaccessible, while the agent of death, the woman has no subject, because no internal focaliser position. (Bronfen, 102).

In stark contrast to the death scenes of the women, which are consistently eroticised, intensified by the use of slow motion, and marked as a stunning spectacle, the death scenes of the men are often treated with great sensitivity and sympathy. In Blade Runner, when Leon is killed by Rachel, it is a very quick sequence: Leon is shot and falls to the ground. His dead body is never presented for viewing. When Batty kills Tyrell by crushing Tyrell's skull, the shot consists of a tight close-up of Batty with only the shadow of Tyrell's head in the foreground as an indistinct blur.

The main emphasis of the scene is on the range of emotions that overcomes Batty as he kills his maker; in doing so, he damns himself to an early death. Thus, the scene is constructed so that while the audience is made to recognise the horror of Tyrell's death, they are also simultaneously encouraged to recognise the tragedy of Batty's situation and to sympathise with him. Indeed, even the soundtrack, which swells into an operatic movement, is used to heighten the intensity and grandeur of the scene. Slow motion sequences highlighting Tyrell's death and lingering shots of Tyrell's body are significantly absent.

Thus it appears that when an attack is made upon men, the scenes are characterised by a tendency to heighten the action and pace of the sequence with fast editing and short takes. There appears to be a conscious attempt to heighten and extend the scenes in which women are attacked and threatened in contrast to the much more energetically paced sequences in which men are threatened and killed. The implication appears to be that while a dead woman may make an interesting and grotesque spectacle, the image of a dead man is not to be treated so commonly. I suggest that this is because the sight of a woman being menaced and threatened is considered more acceptable and potentially more pleasurable for the (male) audience than is the sight of men being menaced and destroyed. It has long been taken for granted that the audience of science-fiction action 
movies are male, thus, these films appear to be constructed to appeal to a male audience by advocating largely male ideologies and concerns.

Thus, when the audience is presented with the sight of a dead man, the treatment of the scenes is significantly different from those of the dead women. The only time in Blade Runner that the image of a dead man is the focus occurs upon Batty's death. The scene is significantly devoid of violence and fear. Batty has just redeemed himself by saving Deckard, whom he just moments before had been hunting. Having pulled Deckard to safety, Batty quietly and calmly sits in the roof and declares, "Time to die". The image we have of Batty is thus marked with dignity, acceptance and courage, and there is none of the grotesque shrieking and thrashing associated with the women's deaths. In death, Batty's character gains grandeur and stature.

Indeed, even the posture that Batty assumes in death resembles that of the enlightened Buddha, sitting with his face downcast, his legs folded under him, calm and impassive to the rain that falls upon him. At the point of death, there is even the highly symbolic image of a dove, released from Batty's hand, flying up into a suddenly clear, brightening sky. In death, Batty's body has symbolic meaning, suggesting redemption, and enlightenment. This is in sharp contrast to the "broken doll" bodies of the women which emphasise the idea that female bodies are merely empty, meaningless objects. That there is a vast difference in the treatment of the death scenes of the men and women is undeniable, and this is another indication of the way women are consistently defined in clearly negative ways while the men in films are given much more complex, sympathetic portrayals.

We can see that the association of femininity and death is an enduring tradition. It is one in which women are continually objectified and spectacularised by the use of such techniques as slow- motion, the manipulation of the soundtrack and the highly conscious, controlled construction of the images. At the same time, the violence and horror of a woman's death is often carefully obscured or muted, generally by marking the woman as a threatening, destructive aggressor, a representative of Otherness who must be eliminated so that order and stability can be restored. In addition, the death of a woman often has great significance and meaning for her survivors; often, her death is dismissed or ignored in favour of examining or focusing upon the reaction and response of the (male) survivor. Portraying the death of a woman also allows for the convenient displacement of all that is evil, negative and undesirable onto her dead body, while allowing the positive, admirable, desirable qualities to be associated with the (male) survivor. Essentially, the death of a woman can be read as either a means of controlling the evil and deviance she is made to represent, or a means of establishing male power, strength and superiority over female weakness, helplessness and inferiority.

[Blade Runner, directed by Ridley Scott, is based on the short story Do Android Dream of electric Sheep by Philip K. Dick and was written for the screen by Hampton Fancher and Davis Poples.]

\section{Notes}

1. Blade Runner (1982; The Director's Cut, 1992) tells the tale of a group of escaped replicants (ie artificial humans created for 'off-world' labour) who have returned to Earth in defiance of a law banning them from doing so. Their aim is to seek out their maker and demand "more life" (replicants are created with a built-in maximum four-year life span). In response to their presence, Earth authorities force a special police officer, a Blade Runner -- Rick Deckard, out of retirement to track down and destroy them before they can do too much harm.

2. Significantly, all the females in the film are replicants, man-made "pleasure units" and/or "assassins".

3. The concept of the "male gaze" was developed by E. Ann Kaplan. See "Is the Gaze Male?" in her book Women and Film: Both Sides of the Camera.

4. See de Lauretis' "The Violence of Rhetoric. Considerations on Representation and Gender" in her book Technologies of Gender. Essays on Theory, Film and Fiction in which she discusses the relationship between representations of violence and notions of gender arguing that any representation of violence is inherently en- gendered and that the meaning of the representation of violence is conditioned by the gender of both violator and the object being violated. 


\section{References}

Bronfen, Elisabeth. Over Her Dead Body. Death, Femininity and the Aesthetic. Manchester: Manchester University Press, 1992.

Bryson, Norman. Vision and Painting. The Logic of the Gaze. New Haven: Yale University Press, 1983.

de Lauretis, Teresa. "The Violence of Rhetoric: Considerations on Representation and Gender" in Technologies of Gender. Essays on Theory, Film and Fiction. Bloomington: Indiana University Press, 1987. 31 50.

de Quincey, Thomas. "Joan of Arc" in The Collected Writings Vol V. Ed. D. Masson. London, 1897.

Gilman, Sander. Difference and Pathology. Stereotypes of Sexuality. Ithaca: Cornell University Press, 1985.

Mérimée, P. "Carmen" in Nouvelles II. Paris, 1983.

Millett, Kate. Sexual Politics. New York: Avon, 1969.

Poe, Edgar Allen. "The Philosophy of Composition" in Essays and Reviews. New York: Literary Classics of the United States, 1984.

Scott, Ridley. Blade Runner, USA: 20th Century-Fox, 1982.

\section{Author Information}

Valerie Su-Lin WEE teaches Film Studies in the Department of English Language and Literature at the National University of Singapore. Her main research interests include Film and Cultural Studies, Gender Studies and Science-fiction and Fantasy Literature. 